\title{
The Effect of Interfacial Interactions on a Structure and Properties of Polyurethane Elastomer/Poly(Vinyl Chloride) Blends
}

\author{
T. L. Malysheva ${ }^{1}$, S. V. Golovan ${ }^{1}$, D. L. Starokadomsky ${ }^{1,2}$ \\ ${ }^{1}$ Institute of Macromolecular Chemistry of the NAS of Ukraine \\ ${ }^{2}$ O.O. Chuiko Institute of Surface Chemistry of the NAS of Ukraine, Ukraine \\ E-mail: stard1@mail.ru
}

Received August 10, 2011; revised September 12, 2011; accepted September 25, 2011

\begin{abstract}
The effect of chemical structure of segmented poly(urethane-urea)s on its interfacial interactions with poly(vinyl chloride) as well as supramolecular structure and the properties of prepared composites has been studied. A direct influence of flexible and rigid segments of elastomers on a compatibility, structure and the physical-mechanical properties of poly(urethane-urea)/poly(vinyl chloride) blends was investigated. A formation of intermolecular hydrogen bonds network in the poly(urethane-urea)/poly(vinyl chloride) systems was evaluated by FTIR analysis. Morphology studies have shown the effect of interfacial interactions on a size of thermoplastic phase dispersed within elastomer matrix. Obtained poly(urethane-urea)/poly(vinyl chloride) micro- and nanocomposites have improved tensile properties.
\end{abstract}

Keywords: Polymer Composites, Compatibility, Microphase Separation, Glass Transition, Hard Domains, Crystallites, Associates, H-Bonds, Urethane-Urea Groups, Interfacial Interactions

\section{Introduction}

Recently, interfacial non-covalent interactions in polymer-polymer systems have attracted the attention because of possibilities to control physical-mechanical characteristics of the polymer materials in accordance to requirements. It could be achieved by a formation of stable supramolecular structure of the blends with enhanced interface adhesion and optimal dispersity of the components. Strong interfacial interactions, which directly depend on chemical, thermodynamic and morphological features of the systems, increase contact surface area, and improve dispersability of the components, and simultaneously decrease the sizes of dispersed phase to nano-level, leading to the formation of nanocomposites.

Among polymer blends, thermoplastic/elastomer blends are particularly interesting due to simplified control of physical-mechanical characteristics of the blends over a wide range by varying their composition and preparation conditions. Polyurethaba elastomers are commonly modified by introducing poly(vinyl chloride) (PVC) to produce flexible materials with enhanced chemical, hydrolytic and environmental stability, and improved fire resistance [1].

Overview of literature sources has shown that heterogeneous structure of binary polyurethane-based systems greatly depends on the chemical structure of immiscible flexible and rigid segments of polyurethane elastomers [2-10]. Presence of chlorine- and oxygen-containing polar functional groups, which could form strong intermolecular physical bonds network, significantly affect the interactions of the components, structurization processes and physical-mechanical properties of the polymer composites. Due to intermolecular hydrogen bonding between ester carbonyl groups of polyurethane and active $\alpha$-hydrogen of PVC chains the ester-based polyurethanes are more compatible with PVC component compared to polyurethanes that contain ether segments in the main chain [8].

Poly(ether-urethane)s synthesized from oligooxypropylene glycol (OPG) are immiscible with PVC and its blends are characterized by poor mechanical properties in all compositional range. Oligooxytetraethylene glycol (OTMG) segments of poly(ether-urethane)s are partially compatible with PVC resulting in increased glass transition temperature of corresponding flexible segments. 
Poly(ester-urethane)s with adipic acid/glycol based flexible oligoester segments form fully heterogeneous blends with poly(vinyl chloride) component independently from preparation techniques $[9,10]$. Increasing polar urethane groups content in elastomer main chain reduces compatibility of the components of corresponding polymer systems [11]. There are only few works related to influence of rigid segments of polyurethanes on its compatibility with PVC polymer. Even though PVC suppresses the segregation of rigid segments in polyurethane elastomers, Xiao et al [8] show that polyurethane based on consider polyurethane based on 4, 4'-diphenylmethane diisocyanate (MDI)/1, 4-butanediol segments are immiscible with PVC. Enhanced compatibility of the components could be detected when highly polar 4, 4'-diaminodiphenylmethane based rigid segments are introduced into poly-(urethaneurea) elastomer macromolecules [12].

This paper investigates the influence of chemical structure of segments of poly(urethane-urea)s on the compatibility with poly(vinyl chloride) and the structureproperties relationships in these polymer blends.

\section{Experimental}

\subsection{Materials}

For synthesis of poly(urethane-urea)s (PUU), oligomeric diols such as oligooxypropylene glycol $\left(\mathrm{OPG} ; \mathrm{M}_{\mathrm{w}}=\right.$ $1000)$, oligooxytetramethylene glycol (OTMG; $\mathrm{M}_{\mathrm{w}}=$ $1000)$ and poly(ethylene-butylene)adipate (PEBA; $\mathrm{M}_{\mathrm{w}}=$ 2000) were used. As urethane constituent a pure 2,4-toluene diisocyanate (2,4-TDI) or mixture of isomers 2,4- and 2,6-toluene diisocyanates (2,4-TDI/2,6-TDI; $65 / 35$ by weight) were selected. N,N-dimethylformamide (DMF) was distilled under reduced pressure and deionized water was used. Other initial components were purified by widely used conventional methods. Poly(vinyl chloride) (PVC) with molecular weight of $8.0 \times 10^{4}$ (by viscosimetry) and chlorine content of 56.3 wt.\% was taken for preparation of the polymer composites.

\subsection{Characterization}

Thermophysical properties of the samples were studied using differential scanning calorimeter DSC-2M (Kievpribor, Ukraine) in the temperature range from 173 to 473 $\mathrm{K}$ with a programmed heating rate of $2 \mathrm{~K} / \mathrm{min}$. Following parameters of the samples were determined: glass transition temperatures $\left(\mathrm{T}_{\mathrm{g}}, \mathrm{K}\right)$, heat of fusion $\left(\mathrm{Q}_{\mathrm{f}}, \mathrm{J} / \mathrm{g}\right)$, degree of crystallinity $\left(\mathrm{X}_{\mathrm{cr}}, \%\right)$ and melting point $\left(\mathrm{T}_{\mathrm{m}}, \mathrm{K}\right)$.

Chemical structure of the components and physical bonds network formed in the prepared polymer blends were evaluated via FTIR analysis using Bruker Tensor ${ }^{\circledR}$ 37 FTIR spectrometer in the spectral region of $400-4000$ $\mathrm{cm}^{-1}$.

In order to characterize micro- and nano-scale heterogeneity of PUU/PVC, samples were characterized by examining samples sputter-coated with gold film of 5-10 $\mathrm{nm}$ thickness in a scanning Electron Microscope (JEOL JSM 6060 LA) Scanning Electron Microscope at an accelerating voltage of $30 \mathrm{kV}$.

Tensile tests were performed on dumbbell-shape specimens at ambient temperature at a crosshead speed of $35 \mathrm{~mm} / \mathrm{min}$ using an FU-1000 universal testing machine (Kazan', Russia). The average data from five tests are given in this work. Tensile strength at break, $\sigma_{b}$, modulus at $100 \%$ elongation, $\mathrm{E}_{100}$, elongation at break, $\varepsilon_{\mathrm{b}}$, and residual elongation, $\varepsilon_{\text {res }}$, were measured.

\subsection{Synthesis of Prepolymers}

Prepolymers for synthesis poly(urethane-urea)s were synthesized from olygomeric diols (OPG, OTMG or PEBA) and aromatic diisocyanates (2,4-TDI or 2, 4-TDI/2, 6-TDI) by a conventional diisocyanate/diol method.

\subsection{Synthesis of Poly(Urethane-Urea)s}

PUUs have been synthesized in DMF solution from as-prepared prepolymers and water as typical chain extender according to two-step method described elsewhere [13]. Compositions of prepared poly(urethaneurea)s was summarized in Table 1.

Poly(urethane-urea) samples with thickness of 10-15 and 200-300 $\mu \mathrm{m}$ were prepared by film casting technique on a Teflon substrate from DMF polymer solutions. The composite films were dried at $323 \mathrm{~K}$ in an oven to a constant weight.

\section{Results and Discussion}

In Table 2 the basic thermophysical parameters of initial poly(urethane-urea)s as well as prepared PUU/PVC blends are presented.

Microphase separation between flexible and rigid segments of pure PUU-1 leads to appearance of two glass transition temperatures: (i) glass transition temperature of amorphous oligoether phase $\left(\mathrm{T}_{\mathrm{g} 1}\right)$ and (ii) relaxation of rigid domains $\left(\mathrm{T}_{\mathrm{g} 2}\right)$. $\mathrm{PVC}$ component has glass transition temperature $\left(\mathrm{T}_{\mathrm{g} 3}\right)$ at $343 \mathrm{~K}$. PUU-1 based polymer blends containing 30 and $70 \mathrm{wt} \% \mathrm{PVC}$ are characterized by presence of two relaxations due to typical biphasic structure of the compositions.

For PUU-1/30PVC blend with $30 \mathrm{wt} . \%$ of PVC 
Table 1. Compositional characteristics of synthesized poly(urethane-urea)s.

\begin{tabular}{ccccc}
\hline Sample & $\begin{array}{c}\text { Oligomeric } \\
\text { ether/ester }\end{array}$ & Diisocyanate & $\begin{array}{c}\text { Rigid segments } \\
\text { content }[\%]\end{array}$ & Intrinsic viscosity $(\eta)\left[\mathrm{cm}^{3} / \mathrm{g}\right]$ \\
\hline PUU-1 & OPG & 2,4-TDI/2,6-TDI & 26.8 & 0.08 \\
PUU-2 & OTMG & 2,4-TDI & 26.8 & 0.061 \\
PUU-3 & PEBA & 2,4-TDI/2,6-TDI & 8.0 & 0.120 \\
\hline
\end{tabular}

Table 2. DSC ${ }^{\text {a) }}$ characteristics of pure PUUs and PUU/PVC blends.

\begin{tabular}{ccccccccc}
\hline Composition & $\begin{array}{c}\mathrm{PVC} \\
\text { content } \\
{[\mathrm{wt} . \%]}\end{array}$ & $\begin{array}{c}\mathrm{T}_{\mathrm{g} 1} \\
{[\mathrm{~K}]}\end{array}$ & $\begin{array}{c}\mathrm{T}_{\mathrm{g} 2} \\
{[\mathrm{~K}]}\end{array}$ & $\begin{array}{c}\mathrm{T}_{\mathrm{g} 3} \\
{[\mathrm{~K}]}\end{array}$ & $\begin{array}{c}\mathrm{T}_{\mathrm{g} 4} \\
{[\mathrm{~K}]}\end{array}$ & $\begin{array}{c}\mathrm{Q}_{\mathrm{f}} \\
{[\mathrm{J} / \mathrm{g}]}\end{array}$ & $\begin{array}{c}\mathrm{X}_{\mathrm{cr}} \\
{[\%]}\end{array}$ & $\begin{array}{c}\mathrm{T}_{\mathrm{m}} \\
{[\mathrm{K}]}\end{array}$ \\
\hline PUU-1 & - & 248 & 343 & - & - & - & - & - \\
PUU-1/30PVC & 30 & 258 & - & 356 & - & - & - & - \\
PUU-1/70PVC & 70 & 248 & - & 328 & - & - & - & - \\
PUU-2 & - & 224 & - & - & - & - & - & - \\
PUU-2/30PVC & 30 & 245 & - & 350 & 312 & - & - & - \\
PUU-3 & - & 238 & - & - & - & 20,7 & 5,8 & 328 \\
PUU-3/30PVC & 30 & 254 & - & - & - & 5,3 & 1,5 & 323 \\
PUU-3/40PVC & 40 & 278 & - & - & - & - & - & - \\
PUU-3/70PVC & 70 & 303 & - & 362 & - & - & - & - \\
\hline
\end{tabular}

a) the data from a second scan was analyzed to eliminate thermal prehistory of the samples

content the $\mathrm{T}_{\mathrm{g} 1}$ of elastomer matrix increases from 248 to $258 \mathrm{~K}$. Relaxation transition at higher temperatures $\left(\mathrm{T}_{\mathrm{g} 3}\right)$ related to combined transformation (degradation) of domain structure of PUU-1 elastomer and dispersed PVC phase. The increase in $T_{\mathrm{g} 3}$ is due to the restriction of segmental mobility of PVC polymer chains as a result of their intermolecular interactions with rigid segments of the elastomer at the interface. For PUU-1/70PVC blend, $\mathrm{T}_{\mathrm{g} 3}$ decreases to $328 \mathrm{~K}$, whereas $\mathrm{T}_{\mathrm{g} 1}$ (relaxation of oligoether segments) of dispersed elastomer phase is essentially same as in the initial PUU-1. Enhancing mutual diffusion of macromolecules of both polymers because of its interactions at the interface should increase $\mathrm{T}_{\mathrm{g} 1}$, while a degradation of domain structure of elastomer phase may initiate increasing a segmental mobility of oligoether segments and decreasing $\mathrm{T}_{\mathrm{g} 1}$. Probably, a basic reason of the lower $T_{g 1}$ is partial degradation of a structure of associated hard domains in dispersed PUU-1 phase. The changes observed for glass transition temperatures may lead to improvement of interface adhesion in studied biphasic polymer systems.

PUU-2 elastomer is characterized by single glass transition temperature of oligoether segments. This suggests reduced segregation of asymmetric 2,4-TDI based rigid segments into hard domains and a formation of smaller aggregates, which form fluctuated structure of physical bonds network. It is clearly seen that enhancing compatibility of PUU-2 with PVC component (at 30 wt.\% of PVC) induces an appearance of new relaxation of mixed phase $\left(\mathrm{T}_{\mathrm{g} 4}\right)$. Abnormal decreases in the density of the blends with $15-50 \mathrm{wt} . \%$ of PVC is attributed to a decrease in the macromolecular packing density that results from the poor mixing of the components at the interface and a formation of disarranged interface region (Figure 1). A density of typically biphasic PUU-1/PVC composites has an additive behavior that suggests poor compatibility of the components in the heterogeneous systems.

It is known that PEBA oligoester is immiscible with PVC [14] and the blends of PVC with polyurethane based on PEBA and MDI/1, 4-butanediol rigid segments are typically biphasic systems [9]. Studies on thermophysical properties of PEBA based pure PUU-3 elastomer and PUU-3 containing composites have shown

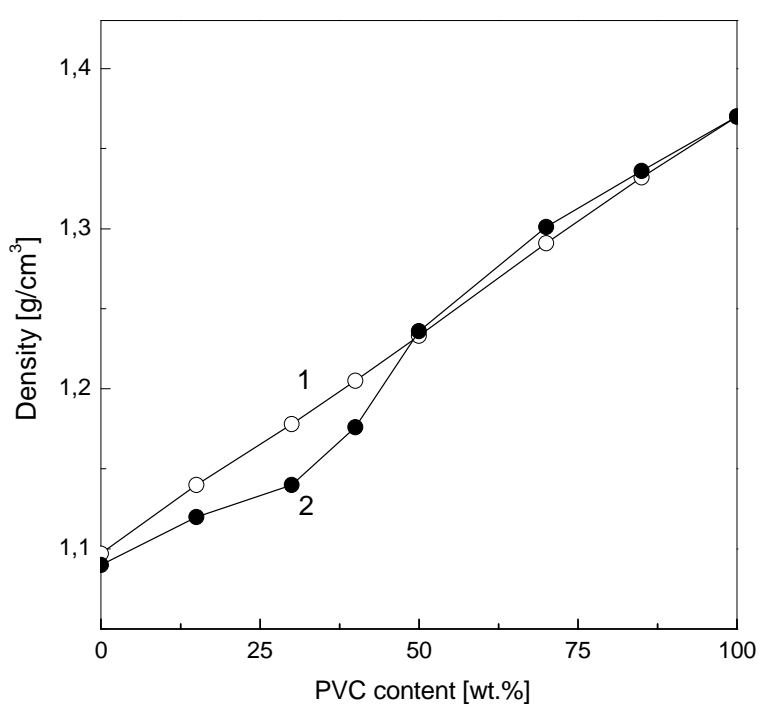

Figure 1. Density versus PVC content plots for PUU-1/PVC (1) and PUU-2/PVC (2) composites. 
that introducing PVC into PUU-3 elastomer matrix decreases the heat of fusion $\left(\mathrm{Q}_{\mathrm{f}}\right)$, the degree of crystallinity $\left(\mathrm{X}_{\mathrm{cr}}\right)$ and crystallites size, and restricts the segmental mobility of PEBA oligoester segments. The composites with PVC content below $40 \mathrm{wt} \%$ are characterized by suppressed crystallization of flexible segments and the blends have only single broad glass transition temperature. This suggests the formation of strong physical bonds network resulted in enhancing compatibility between components of PUU-3/PVC blends. In other words, highly polar urethane-urea rigid segments of PUU-3 elastomer substantially enhance a compatibility between the components of the blends. When the PVC content reaches 70 wt.\%, phase separation occurs as indicated by the appearance of relaxation transition of PVC constituent were clearly identified.

The interfacial interactions in the pure PUUs and PUU based polymer blends were found and thoroughly studied by FTIR spectroscopy analysis. Participation of urethane-urea functional groups in hydrogen bonding (H-bonding) processes was estimated by comparative analysis of $\mathrm{NH}$ stretching vibrations band $\left(\mathrm{v}_{\mathrm{sNH}}\right)$ in the spectral region of 3500-3200 $\mathrm{cm}^{-1}$. The involvement of C $=\mathrm{O}$ groups in hydrogen bonds network was determined by analysis of amide I band in the region of 1800-1600 $\mathrm{cm}^{-1}$. The presence of urea groups in PUUs mainchain changed the polarity of rigid and flexible segments of polymer and hydrogen bonding between $\mathrm{C}=\mathrm{O}$ of urea and $\mathrm{NH}$ groups of rigid segments. As an internal standard the reference aromatic $\mathrm{C}=\mathrm{C}$ stretching vibration band $(\mathrm{vC}=\mathrm{C})$ at about $1600 \mathrm{~cm}^{-1}$ was selected.

Basic FTIR characteristics of the functional groups, which participate in H-bonding, have been summarized in Table 3. Wavenumber band position (v), optical density (D), a quantity of self-associated $\mathrm{C}=\mathrm{O}$ of urea $(\alpha)$ and the integrated intensity of the hydrogen bonded $\mathrm{NH}_{\mathrm{b}}$-groups $\left(\mathrm{A}_{\mathrm{NH}}\right)$ were determined and analyzed.

In FTIR spectrum of PUU-1 sample (Figure 2) the characteristic bands of self-associated $\mathrm{H}$-bonded $\mathrm{C}=\mathrm{O}$ of urea (referred as $\mathrm{C}=\mathrm{O}_{\mathrm{cb}}$ ) and urethane (referred as $\mathrm{C}$ $=\mathrm{O}_{\mathrm{ub}}$ ) functional units of rigid segments of the PUU macromolecules are identified. Additionally, the presence of non-bonded ("free") carbonyls of urethane and $\mathrm{NH}$ of urethane $\mathrm{H}$-bonded with ether fragments were also determined.

The quantity of self-associated $\mathrm{C}=\mathrm{O}_{\mathrm{cb}}$ groups of urea ( $\alpha$ value) was calculated from spectral data as a ratio of band areas of $\mathrm{C}=\mathrm{O}_{\mathrm{cb}}$ and all $\mathrm{C}=\mathrm{O}$ groups of poly(urethane-urea). The $\alpha$ value for pure PUU-1 was calculated as 0.104 . Addition of 30 wt.\% PVC to PUU-1 decreases $\alpha$ value by $15 \%$ increases the absorbance of $\mathrm{C}$ $=\mathrm{O}_{\mathrm{f}}$ by $5.8 \%$, while the intensity of $\mathrm{C}=\mathrm{O}_{\mathrm{ub}}$ at $v=1693$ $\mathrm{cm}^{-1}$ remains unchanged. Despite of the destruction of $\mathrm{NH}^{\delta+\ldots \delta-} \mathrm{O}=\mathrm{C}$ type hydrogen bonds network the integrated intensity of the $\mathrm{A}_{\mathrm{NH}}$ decreases by only $5 \%$.

Thus, the changes in FTIR spectra are indicative of partial destruction of domain structure of elastomer matrix due to interfacial interactions of urethane-urea $\mathrm{NH}$ groups with chlorine function of the PVC thermoplastic. Similar intermolecular hydrogen bonding of $\mathrm{NH}^{\delta+\ldots} \mathrm{Cl}^{\delta-}$ type in PUU/PVC systems was earlier reported earlier[12]. Intermolecular interactions between PVC and rigid segments of PUU increase the $T_{g 3}$ in the blends. Decrease in the intensity of $\mathrm{C}=\mathrm{O}_{\mathrm{cb}}$ band by 52 $\%$ and large increase in the optical density of $\mathrm{C}=\mathrm{O}_{\mathrm{f}}$ band (see Figure 3, curve 2) with increasing PVC content up to $70 \mathrm{wt} . \%$ could be due to fewer associated rigid segments. Aforementioned data confirm the DSC results on the effect of partial destruction of associated rigid segments on $T_{g 1}$ in PUU-1/70PVC system.

A much greater influence of dispersed PVC thermoplastic phase has been found on the supramolecular structure of PUU-2 elastomer matrix (Figure 3). The level of association of the urea groups association in OTMG-based PUU-2 is higher than in OPG-based PUU-1. For the PUU-2/30PVC blend, the C $=\mathrm{O}_{\mathrm{cb}}$ content decreases by $80 \%$ and $\mathrm{A}_{\mathrm{NH}}$ value decreases by $12 \% . \mathrm{C}=\mathrm{O}_{\mathrm{cb}}$ content reaches $80 \%$ and $\mathrm{A}_{\mathrm{NH}}$ value reduces by $12 \%$. Stretching vibrations band of $\mathrm{NH}$ groups shifts from 3302 to $3298 \mathrm{~cm}^{-1}$ and a shoulder appears in the region of $3420-3380 \mathrm{~cm}^{-1}$ due to stretching vibrations of "free" (non-bonded) NH groups. These changes provide evidence for extensive

Table 3. FTIR spectral characteristics of PUUs and PUU based polymer blends.

\begin{tabular}{cccccccc}
\hline \multirow{2}{*}{ Sample } & \multicolumn{3}{c}{$\mathbf{C =} \mathbf{O}_{\mathbf{c b}}$} & \multicolumn{2}{c}{$\mathrm{C}=\mathrm{O}_{\mathrm{f}}$} & \multicolumn{2}{c}{$\mathrm{NH}_{\mathrm{b}}$} \\
\cline { 2 - 8 } & $\begin{array}{c}v \\
{\left[\mathrm{~cm}^{-1}\right]}\end{array}$ & $\begin{array}{c}\mathrm{D}_{\mathrm{i}} \\
{[\text { a.u. }]}\end{array}$ & $\alpha$ & $\begin{array}{c}v \\
{\left[\mathrm{~cm}^{-1}\right]}\end{array}$ & $\begin{array}{c}\mathrm{D}_{\mathrm{i}} \\
{[\mathrm{a} . \mathrm{u} .]}\end{array}$ & $\begin{array}{c}v \\
{\left[\mathrm{~cm}^{-1}\right]}\end{array}$ & $\mathrm{A}_{\mathrm{NH}}$ \\
\hline PUU-1 & 1638 & 1,46 & 0,104 & 1730 & 3,36 & 3290 & 8,1 \\
PUU-1/30PVC & 1638 & 1,16 & 0,088 & 1728 & 3,57 & 3288 & 7,8 \\
PUU-1/70PVC & 1639 & 0,84 & 0,050 & 1730 & 8,05 & 3290 & 6,8 \\
PUU-2 & 1643 & 1,05 & 0,150 & 1730 & 1,73 & 3302 & 4,1 \\
PUU-2/30PVC & 1644 & 0,22 & 0,015 & 1728 & 1,92 & 3298 & 3,6 \\
PUU-2/70PVC & 1652 & 0,36 & - & 1729 & 1,95 & 3303 & 3,2 \\
\hline
\end{tabular}




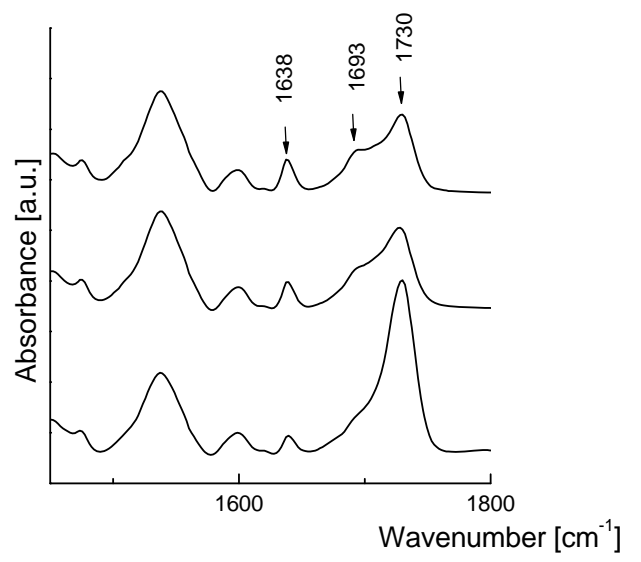

Figure 2. FTIR spectra of PUU-1 (1) and PUU-1/PVC composites with 30 wt.\% (2) and 70 wt.\% (3) of PVC.
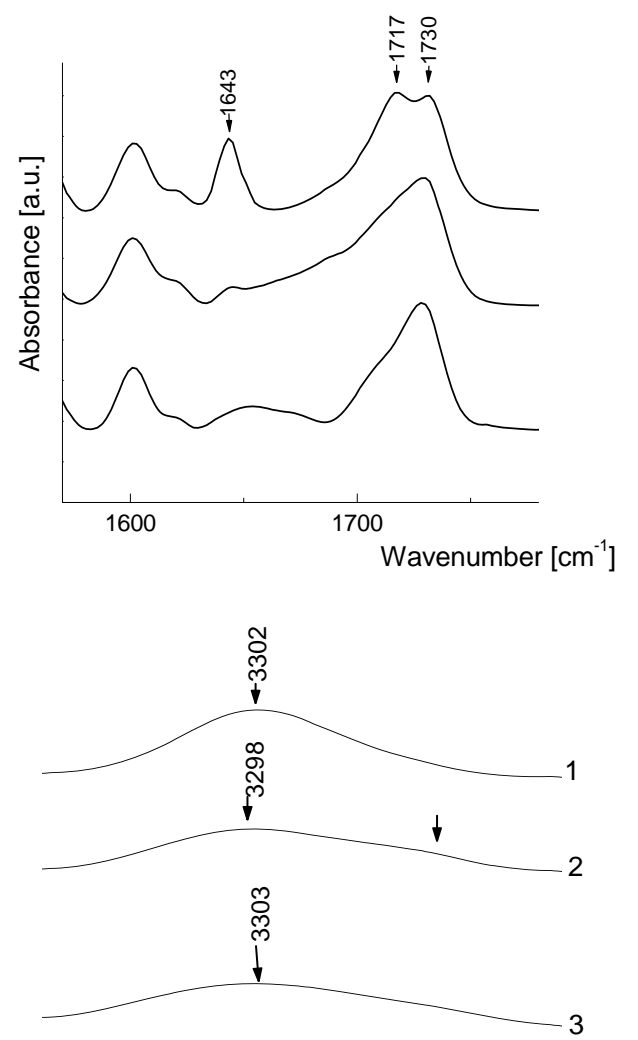

3300

Figure 3. FTIR spectra of pure PUU-2 (1), PUU-2/30PVC (2) and PUU-2/70PVC (3) compositions.

destruction of intramolecular hydrogen bonds network in elastomer matrix as a result of stronger interface of $\mathrm{NH}^{\delta+\ldots} \mathrm{Cl}^{\delta-}$ interactions at the interfacial layer.

Introducing PUU elastomer in PVC thermoplastic matrix (PUU-2/70PVC sample) gives rise to a broad band of weakly associated and "free" urea groups in the FTIR spectrum (Figure 3, curve 3). The decrease in $A_{\mathrm{NH}}$ and a shift of stretching vibrations band of $\mathrm{NH}$ groups to high wavenumbers confirm a reduction in both the interfacial interactions and the compatibility between the blend components.

FTIR spectra of initial PUU-3, which was synthesized using oligoester constituent (in contrast to both oligoether based PUU-1 and PUU-2), and PUU-3 containing composites are shown in Figure 4.

In the spectrum of pure PUU-3, there is an intense $\mathrm{C}=$ $\mathrm{O}_{\mathrm{f}}$ band at $v=1727 \mathrm{~cm}^{-1}$ and a weak $\mathrm{NH}_{\mathrm{b}}$ band at $v=$ $3340 \mathrm{~cm}^{-1}$. This shows that a major part of carbonyls are "free", indicating a low level of participation of $\mathrm{C}=\mathrm{O}$ in H-bonding processes. In FTIR the spectrum of PUU-3/40PVC, an intense band due tostretching vibrations of $\mathrm{H}$-bonded carbonyls appears at $1723 \mathrm{~cm}^{-1}$ as a result of interfacial interactions between $\mathrm{C}=\mathrm{O}$ of ester groups of PUU-3 and active $\alpha$-hydrogen of PVC chains. Increase in the integrated intensity of $\mathrm{NH}_{\mathrm{b}}$ band by $68 \%$ is due to interactions between $\mathrm{NH}$ of urea and chlorine of PVC. Thus, hydrogen bonds are formed in the blend mainly via $\mathrm{NH}^{\delta+\ldots \delta-} \mathrm{O}=\mathrm{C}$ bonds and partially, from $\mathrm{NH}^{\delta+\ldots} \mathrm{Cl}^{\delta-}$ bonds (due to small content of urea groups). DSC data show that the prepared blend is a single phase system. Increasing PVC content to $70 \mathrm{wt} . \%$ increases the fraction of "free" $\mathrm{C}=\mathrm{O}$ and decreases $\mathrm{A}_{\mathrm{NH}}$ value as a result of the reduced compatibility between the blend components and the formation of heterogeneous structure of the blends occurs.

The FTIR spectrum of thermoplastic/elastomer blends at $30 \mathrm{wt} . \%$ of elastomer content in the spectral region of $\mathrm{C}-\mathrm{Cl}$ stretching vibrations is presented in Figure 5. The relative intensities of the bands at 615 and $638 \mathrm{~cm}^{-1}$ are routinely used for the estimation of the degree of crystallinity, stereoregularity and conformation rearrangements in PVC polymer. The ratio of the optical densities of the $\mathrm{C} 1$ stretching bands at $638 \mathrm{~cm}^{-1}\left(\mathrm{D}_{638}\right)$ from the crystalline region of syndiotactic polymer and at $615 \mathrm{~cm}^{-1}\left(\mathrm{D}_{615}\right)$ from the atactic polymer is generally used for evaluation of an index of crystallinity $(\mathrm{K})$ of PVC using Equation 1.

$$
K=D_{638} / D_{315}
$$

The degree of crystallinity (globular crystallites) of $\mathrm{PVC}$, is $10 \%$ from wide angle $\mathrm{X}$-ray diffraction analysis, and the $K$ value is 1.04 from FTIR data. Introducing 30 wt.\% of poly(urethane-urea) elastomer into PVC matrix reduces $\mathrm{K}$ value to $0.95,0.92$ and 0.88 for PUU-1, PUU-2 and PUU-3, respectively. This large effect on the conformation and the crystallinity of PVC matrix suggests that has dispersed PUU-3 phase is dispersed in the 


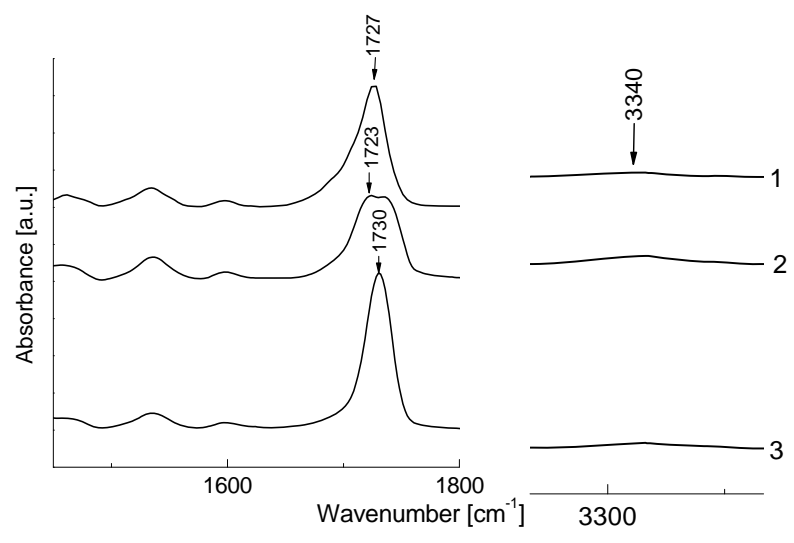

Figure 4. FTIR spectra of PUU-3 (1), PUU-3/40PVC (2) and PUU-3/70PVC (3) samples.

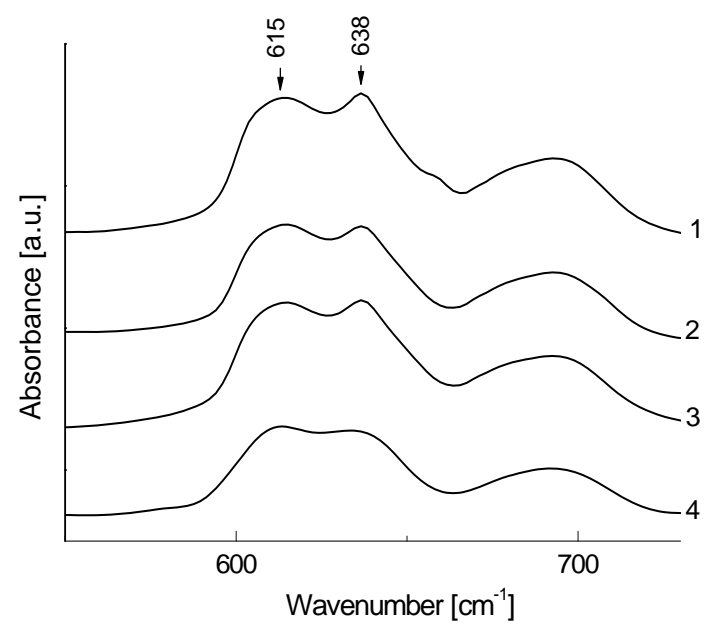

Figure 5. FTIR spectra of PVC (1), PVC/30PUU-1 (2), PVC/30PUU-2 (3) and PVC/30PUU-3 composites (4).

PVC matrix.

Finally, based on FTIR spectral analysis, it can be deduced that the chemical structure of poly(urethane-urea) significant influence on interfacial interactions (hydrogen H-bonds network), which in turn affects to structurization processes and the final properties of the polymer blends.

Influence of interfacial interactions on morphology of the composites were evaluated by analyzing the samples in a scanning electron microscope. SEM micrographs of heterogeneous PUU-1/30PVC composition showed an average particle size of $1-2 \mu \mathrm{m}$ (Figure 6(a)). The stronger interfacial interactions in PUU-2/30PVC system substantially reduce an average particles size of dispersed PVC phase to $80-200 \mathrm{~nm}$ (Figure 6(b)). PUU-3/30PVC sample was characterized by fine dispersion of the components at molecular level and the blend could be referred as typical nanocomposite

\section{(Figure 6(c)).}

Mechanical properties of poly(urethane-urea)/poly (vinyl chloride) composites are presented in Figure 7. Tensile strength at break $\left(\sigma_{b}\right)$ values for PUU-1/PVC composites is higher than that due to additivity alone because of the enhanced interfacial adhesion between the components. $\sigma_{\mathrm{b}}$ in PUU-2/PVC and PUU-3/PVC compositions containing $30-50 \mathrm{wt} \%$ of thermoplastic show large compositional dependence. Elasticity mo-n dulus at $100 \%$ elongation $\left(\mathrm{E}_{100}\right)$ for PUU-3 based composition decreases at low ( $\sim 30 \mathrm{wt} . \%) \mathrm{PVC}$ content as a result of decreasing in a crystallinity Elasticity modulus at $100 \%$ elongation $\left(\mathrm{E}_{100}\right)$ for PUU-3 based composition decreases at low ( $\sim 30 \mathrm{wt} . \%)$ PVC content as a result of a decrease in the crystallinity of oligoester segments. In contrast, $\mathrm{E}_{100}$ grows at higher thermoplastic concentrations. From the data presented in Figure 7 it could be seen that basic physical-mechanical properties of the micro- and nano-structurized poly-(urethane-urea)
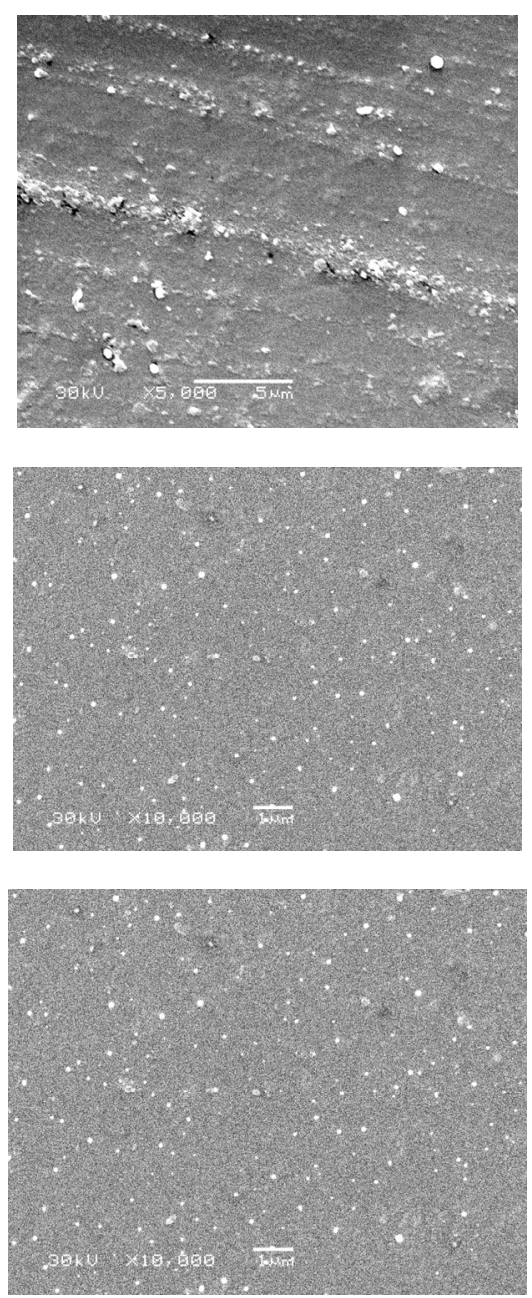

Figure 6. SEM images of PUU-1/30PVC (a), PUU-2/30PVC (b) and PUU-3/30PVC (c) compositions. 

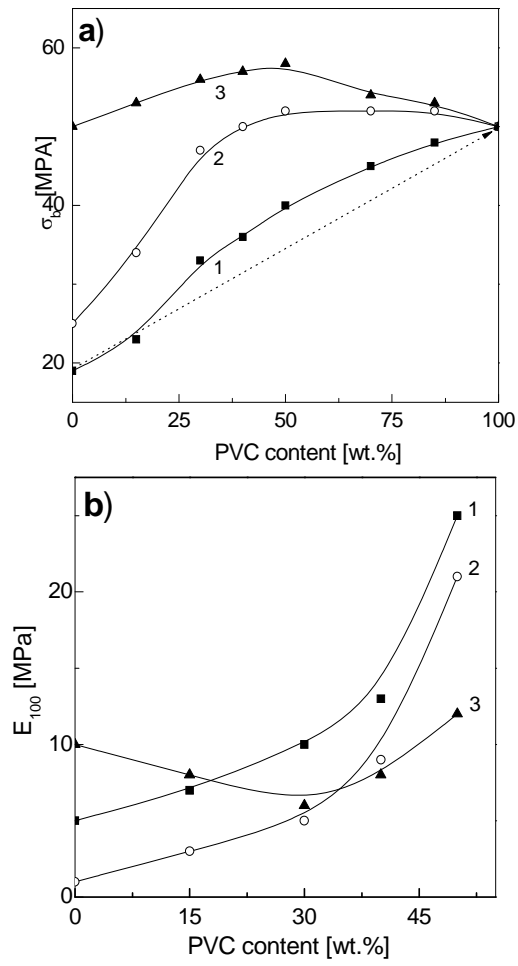

Figure 7. Tensile strength at break, $\sigma_{b}(a)$ and modulus $E_{100}$ (b) versus concentration dependences for PUU-1 (1), PUU-2 (2) and PUU-3 (3) based compositions.

/poly(vinyl chloride) thermoplastic elastomers containing $30-40$ wt. $\%$ of PVC are similar to that in well-known commercial polyurethane thermoplastic elastomers.

\section{Conclusions}

The chemical structure of flexible and rigid segments of poly(urethane-urea)s have a large influence on the interfacial interactions and compatibility of poly (urethane-urea) elastomer and poly(vinyl chloride) thermoplastic. An increase in the energetic characteristics of hydrogen bonds networks dramatically reduces the size of dispersed PVC thermoplastic phase in elastomer matrix. This micro- and nano-structurized poly(urethane-urea)/poly(vinyl chloride) thermoplastic elastomers have excellent physical-mechanical properties.

\section{References}

[1] S. Omelchenko and T. Kadurina, "Modified Polyurethanes," Kiev, USSR: Naukova Dumka Edition, 1983.
[2] K. R. Gifford and D. K. Moore, "Study of the Compatibility of Blends of Various Thermoplastic Polyurethane Elastomers with Poly(vinyl chloride) Homopolymer," Plastic and Rubber Materials Application, Vol. 5, No. 4, 1980, pp. 161-164.

[3] C. B. Wang, S. L. Cooper, "Morphology and Properties of Poly(vinyl chloride)-Polyurethane Blends," Journal of Applied Polymer Science, Vol. 26, 1981, pp. 2989-3006. doi:10.1002/app.1981.070260915

[4] N. K. Kalfoglou, "Property-Composition Dependence of Polyurethane-Poly(vinyl chloride) Polyblends," Journal of Applied Polymer Science, Vol. 26, No. 3, 1981, pp. 823-831. doi:10.1002/app.1981.070260308

[5] P. K. Bandyopadhyay and M. T. Shaw, "Viscoelastic and Engineering Properties of Poly(vinyl chloride) Plasticized with Polycaprolactone-Based Polyurethanes," Journal of Applied Polymer Science,Vol. 27, No. 11, 1982, pp. 4323-4335. doi:10.1002/app.1982.070271122

[6] N. T. Sudaryanto and M. Ueno, "Miscibility of Segmented Polyurethane/Poly(vinyl chloride) Blends," Journal of Applied Polymer Science, Vol. 8, 2001, pp. 3022-3029. doi:10.1002/app.2157.abs

[7] T. Malysheva, "Polymer Blends Based on PVC and New Polyurethane Elastomers," Kompozitionne Polymernie Materiali, Vol. 20, No. 1, 1998, pp. 31-36.

[8] F. Xiao, D. Shen and X. Zhang, "Studies on the Morphology of Blends of Poly(vinyl chloride) and Segmented Polyurethanes," Polymer, Vol. 28, No. 13, 1987, pp. 2335-2345. doi:10.1016/0032-3861(87)90396-X

[9] J. Piglowski and T. Skowronski, "Miscibility in PVC-Polyester Blends," Angewandte Makromolekulare Chemie, Vol. 85, 1980, pp. 129-136. doi:10.1002/apmc.1980.050850108

[10] P. H. Chacatrjan, R. S. Kiseleva, J. V. Zelenev and V. Voskresenskij, "Untersuchung der Physikalischen Eigenschaften von Polymer-Kompositen auf Basis von Poly (vinylchlorid) und Urethanelastomeren," Acta Polymerica, Vol. 37, 1986, pp. 483-486. doi:10.1002/actp.1986.010370803

[11] Yu. Lipatov, V. Shilov and V. Bliznyuk, "Peculiarities of Self-Organization in the Production of Interpenetrating Polymer Networks," Vysokomolekulyarnye Soedinenia, Vol. 28, No. 8, 1986, pp. 1712-1718.

[12] T. Malysheva, "Micro- and Nanocomposites of Vinyl Chloride Based Polymers and Polyurethane Elastomers," Polimerni Journal, No. 3, 2010, pp. 171-178.

[13] G. Konoplyanko, I. Kafengauz and E. Petrov, "Chemistry and Technology of Polyurethanes," Vladimir, USSR: Edition of Institute of Synthetic Resins, 1972, pp. 146-154.

[14] J. Ziska, J. Barlow and D. Paul, "Miscibility in PVC-Polyester Blends," Polymer, Vol. 22, No. 7, 1981, pp. 918-923. doi:10.1016/0032-3861(81)90268-8 